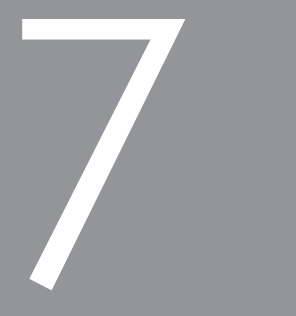

\title{
THE CURRICULUM AS AN INSTITUTION IN HIGHER EDUCATION
}

\author{
Jonathan Jansen
}

This chapter has been reproduced with the kind permission of UCT Press and Stanford University Press. It has been taken from Knowledge in the Blood by Jonathan Jansen: UCT Press, 2009.

When we look back on what we have done, or not done, we realize that it is the knowledge in the blood that has impelled us. ${ }^{16}$

\section{ABSTRACT}

What I contest in this chapter, at heart, is what counts as worthwhile knowledge in a university - 15 years after the official end of apartheid. From a leadership perspective as a first black dean of education at a previously predominantly white Afrikaans university, I illustrate the extreme complexity of transforming the institutional curriculum into a nonracial and non-dominant one. I conclude that to transform the lived curriculum in postapartheid South Africa and to change what people deeply believe about race, identity and knowledge is vastly challenging. At an academically conservative institution, for students and staff alike, curriculum change is painful, and in some instances, impossible. Ironically, the institutional curriculum is more powerful than the documented curriculum and calls for a deeper look into what lies at the foundations of the former. The institutional curriculum appears to be embedded at the level of 'blood knowledge', which refers to the emotional, psychic, social, economic, political and psychological inheritance of an institutional and wider community (Woods 2007). I also use the case of an 'Ubuntu' curriculum at the institution in question to portray the misconceptions and, in some instances, outright ignorance of the sensitivities surrounding the promotion of stereotypes. Inevitably, such actions perpetuate the outdated and ingrained institutional

16 From e-mail correspondence with the Irish poet Macadara Woods who used the phrase in a poem and as the 2007 title of a collection of his poems, Knowledge in the Blood: New and selected poems, Dedalus Press (first published in 2000). 


\section{PART THREE - TEACHING, LEARNING AND THE CURRICULUM}

curriculum. I consequently suggest strategies for curriculum transformation, highlight the complexities regarding curriculum change and record the academic staff responses experienced. My aim with the chapter is ultimately to encourage further research to find out how change can be promoted in syllabic knowledge which is seemingly firmly embedded in institutional knowledge, and which, in turn, is rooted in emotionallyheld social and historical understandings of race and identity in South African higher education.

\section{BLOOD TIES}

The self-assured Western consultant who stepped off a plane in a third world country knew little about avoided asking his hosts for a briefing, demanding instead a simple set of documents with the rationale: Show me your curriculum and I'll tell you who is in power. With this well-told story in mind, I know that disturbing the institutional curriculum is tantamount to touching power. None of my graduate courses in curriculum theory had prepared me as an academic leader for what turned out to be the most difficult task in the transformation of the University of Pretoria and, in particular, its Faculty of Education. For what was codified in the curriculum was not simply information in the text; it was, I would soon discover, knowledge in the blood.

For the original author of the term, the Irish poet Macdara Woods (2007), knowledge in the blood is

[t] he sum total of what we learn (or have to learn - from experience), of love, disappointment, age, loss, and how this knowledge can both make the necessary ongoing human reaffirmation of life and hope possible and at the same time hinder it ... It is almost as though we are carrying psychological antibodies inside us. The knowledge in the blood, however it got there, is as ingrained as a disease - although at the same time it can be truly benign. In this sense the knowledge (which we have been gathering since childhood, as well as having it handed down from before) can be - even at its best - as pitilessly indifferent, as ultimately powerful, and as random in why it propels us in any particular direction, as a microbe...

In this vein, knowledge in the blood for me means knowledge embedded in the emotional, psychic, spiritual, social, economic, political and psychological lives of a community. Such is the knowledge transmitted faithfully to the second generation of Afrikaner students. It is not, therefore, knowledge that simply dissipates like the morning mist under the pressing sunshine of a new regime of truth, for then curriculum change would be a relatively straightforward matter (Jansen 1991a). Knowledge in 
the blood is habitual, a knowledge that has long been routinised in the ways the second generation sees the world, itself and the ways in which it understands others. It is emphatic knowledge that does not tolerate ambiguity, and this dead certainty was long given its authority by a political and theological order than authorised such knowledge as singular, sanctified and sure. But it is also a defensive knowledge that reacts against and resists rival knowledge, for this inherited truth was conceived and delivered in the face of enemies - the English imperialists, the barbarous blacks, the atheistic communists, all of them.

This does not mean that knowledge in the blood cannot change its outer coating and mimic in style and language what is ordered by the new state. Nor does it mean that through the transfusion of new knowledge the authority of received knowledge cannot be overcome. For this reason, knowledge in the blood is used here both as an assertion and a question. As an assertion the phrase draws attention to deeply rooted knowledge that is hard to change; as a question, knowledge in the blood is itself subject to change. ${ }^{17}$

Even so, knowledge in the blood is not easily changed. Afrikaners, in what I shall later call conditional pragmatism, will more energetically than most revise and realign curricula to fit the exacting demands of officialdom and seek to demonstrate responsiveness to the new authorities. But it would be a serious mistake to read bureaucratic responsiveness to the formal demands of reconstruction as altering deeprooted assumptions and beliefs about history, identity, knowledge and change - for the curriculum is, at base, an institutional subject.

\section{CURRICULUM AS INSTITUTION}

What does it mean to speak about curriculum as an institution? ${ }^{18}$ My perspective is inspired by the work of Reid (1999, 2004, 2006) and Terwel and Walker (2004).

17 I am grateful to Sam Wineburg for making the point that knowledge in the blood carries in itself genetic and determinist overtones reminiscent of Nazi ideology, hence my acknowledgment here of the redemptive path open to those who carry such knowledge. Perhaps the invocation of the phrase, as assertion and question, is precisely the emancipatory point in a nationalistic context where blood features prominently in the social discourses of Afrikaner history - such hematological mythology concretised most clearly in the memories of The Battle of Blood River.

18 This perspective on curriculum as institution is inspired by, though making significant elaborations on, the work of the leading theorist of curriculum on the subject, WA Reid. Reid describes and indeed reviews curriculum as institution as something that is socially pervasive, culturally contingent and holding a national character. Curriculum as institution is an abstract idea, "something that is simply there" (Reid 2006:19, Pursuit) apart from its 


\section{PART THREE - TEACHING, LEARNING AND THE CURRICULUM}

It means regarding the curriculum not only as a text inscribed in the course syllabus for a particular qualification, but an understanding of knowledge encoded in the dominant beliefs, values and behaviours deeply embedded in all aspects of institutional life. Knowledge therefore becomes not only what is formally designated for learning, such as in the course syllabus, but what is widely understood within the institution to be acceptable forms of knowledge and recognised ways of knowing that distinguishes one university type (such as the Afrikaans universities) from the rest. To be sure, the course syllabus is an expression of the curriculum as an institution - but it is only one such manifestation of the regnant knowledge dispersed throughout the ceremonies, symbols, rituals, rules, regulations, discourses and countless other cultural transactions within the commonsense of, in this case, the public university.

If therefore an institution is "a socially embedded idea defined by well-known structures" (Reid 2006), then the university curriculum is that idea expressed in multiple ways that include but go beyond the ways of teaching, learning and assessing within a particular institutional context. It encapsulates what most workers within that institutional setting understand to be the character, content and boundaries of knowledge that come with being in that place, the university. It extends to include the understanding by institution dwellers of the particular link between knowledge and authority, about who

expression in organisational structures and processes; yet, it is habits, traditions, as well as organisational arrangements. I am closer to one perspective that he reviews which sees "curriculum as institution as about more than learning in the sense of achieving familiarity with facts and ideas ... skills and competence" (Reid 2006:22) and rather as something shaped by historical values, ideals and purposes (Reid 1999:187). And when curriculum as institution functions in the day-to-day life of an institution, it is indeed in the form of "abstract categories that enter into the consciousness of the community at large" (Reid 2004:92).

Where I depart from WA Reid is in his representation of curriculum as an institution as a consensual matter of democratic institutions set in place by the democratic state and which functions at the service of a democratic society. There is no divided community, society or government in his portrayal of curriculum, institutions or curriculum as institution. Whether in authoritarian or democratic states, I regard the institution as the product of social contests over what kinds of knowledge would be deemed legitimate; that is, institutions are formed in defence of particular positions setting themselves against the ideals, interests and values of competing groups. While historically established, these institutions are never socially settled as they become the subject not only of evolutionary, but also revolutionary change. The contests in the post-apartheid period is in fact a contest over divided institutions, ones established under apartheid - such as the University of Pretoria - and now occupied increasingly by those with different values, histories and ideals about what constitutes legitimate knowledge. Yet, because these are institutions and not simply organisations that succumb to the short-term whims of one or other social interest, changing the embedded knowledge of a university is very difficult indeed. 
possesses knowledge to act on and against others, and who are positioned simply as the recipients of authoritative knowledge.

This is what Amnon Karmon (2007:622-623), in reference to the institutional organisation of knowledge, calls the epistemic environment, where

the institutional level contains within it not only messages regarding ways of relating to learned knowledge, but also powerful messages regarding the very nature of knowledge itself ... this term (an epistemic environment) refers to a comprehensive system of epistemic messages that are conveyed through practices and organizational patters [with] a message that provides us with ideas about the nature of knowledge itself.

Learning this institutional knowledge therefore can lead to a specific qualification if the curriculum is understood to be the achievement of learning outcomes by those who choose (and indeed qualify) to pursue a particular course of study. But learning in an institutional perspective is more than the accumulation of modules and credit hours that signal the attainment of specific kinds of knowledge; it is also learning the concealed knowledges of an institution - about what counts as knowledge in the everyday operations of, in this case, the Afrikaans university; about the penalties and strictures that come with moving outside of this institutionally legitimated knowledge; and about the benefits and advantages that result from 'slotting in' to these dominant knowledge forms without breaking the historical resonances that cement relations between (in this case, white) staff, students, parents and community.

The curriculum in this view is therefore both tangible (course outlines) and intangible (discursive patterns), but throughout it is "a shaping force" (Terwel and Walker 2004) in the lives of those who teach, learn, administer, manage and lead within the institution. It is the knowledge the administrative clerk learns about who not to offend in an institution, which rules to follow and which to ignore, about the written rules and the unwritten rules, and about how to navigate this embedded script without harm to oneself and to one's career. It is the knowledge the young academic learns about what kinds of postures and positions can advance her career and which behaviours can inhibit promotion or even end a career; such knowledge goes way beyond what is written in the administrative guide to promotion for it includes the unspoken but obtainable knowledge about how to advance academically within the peculiarities of that institution. Without access to such embedded knowledge, the newcomer is often exposed and disciplined while the old hands can negotiate these hidden rules for behaviour almost instinctively. In all these examples, the curriculum as embedded 


\section{PART THREE - TEACHING, LEARNING AND THE CURRICULUM}

knowledge, values and beliefs spreads throughout the operational crevices of the institution and transforms the behaviour of campus citizens.

By rendering the curriculum as an institutional subject, it is possible therefore to distinguish one institution from the next when comparing, in this case, the curriculum of different kinds of South African universities (see Cloete et al. 2006; Jansen 2001). The University of Pretoria (UP) and the University of Cape Town (UCT) are among the top three universities in South Africa and are regularly listed among the top 500 institutions in the world. Both universities boast impressive facilities, world class scholars, and high levels of research productivity. Yet, these two institutions are light years away from each other in terms of the curriculum as an institutional category; in fact, they might as well be in different national contexts. The open knowledge system of UCT and the closed knowledge system of UP, both established over 100 years, have in time inscribed very different contours, content and expressions of knowledge in the two institutions so that successfully navigating the curriculum (as defined here) in one institution could spell disaster for a young career in the other institution. So, for example, while the University of Cape Town regularly has openly hostile debates about access (see Benatar 2007a, 2007b; London 2007; Erasmus 2007) and fierce contestations over the institutional curriculum that make riveting reading in the local press, this never happens in the closed knowledge system of the University of Pretoria (Jansen 1998).

Although both institutions were shaped by apartheid and both are subject to the same regulatory policies and measurement matrices from external agencies such as government, an even cursory reading of the quality assurance reports of the two institutions by the same body (the Higher Education Quality Committee of the Council for Higher Education) would reveal the very different inscriptions of knowledge within these two universities. ${ }^{19}$ Knowledge - its character, substance and ambitions - therefore takes on very different forms in these two institutions.

What this means for curriculum change is that it is much more difficult in a place like the University of Pretoria to challenge the very deep assumptions, beliefs and values that hold institutional knowledge in place. It is not so difficult to change the exoskeleton of the institutional curriculum, the kinds of alterations that could impress external agencies such as government and signal alignment with bureaucratic expectations. It is infinitely more difficult to crack the "endoskeleton" (see Terwel and Walker 2004) of the curriculum, that hard surface that holds in place deep understandings, norms and

19 The institutional audit reports are accessible as Executive Summaries for the two institutions and others from the website of the Council on Higher Education at www.che.ac.za. 
commitments that over a century have come to represent settled knowledge within the institution. Here it is important to distinguish the practices of individual innovators or outsiders coming into an institution whose work might very well exist inside of, even challenge, institutional knowledge. As the University of Pretoria slowly opened-up its staffing to those from outside of its immediate community - white Afrikaans-speaking academics - it brought in black deans, black professors and also English-speaking and progressive Afrikaners whose knowledge formation and consciousness were the result of advanced training outside the ambit of the traditional Afrikaans universities.

But these individuals were, for the most part, too small in number and too limited in influence inside a large and complex organisation to erode at its centre what counted as institutional knowledge; and even as they pushed for curriculum change, their efforts were overwhelmed by the inertia of embedded knowledge. Nowhere was the institutional character of knowledge more profoundly expressed than in an official university curriculum called "Ubuntu".

\section{UBUNTU INTRODUCED}

Few words evoke more social confusion in South Africa than the term Ubuntu. A Zulu word translated commonly as "humanity towards others", Ubuntu has had many uses. It has been the subject of a crass commercialism selling books and merchandise that market 'humanity' for profit in post-apartheid society (see Mbigi 1997). Ubuntu was once mobilised for political purposes by the conservative Inkatha cultural movement and later political party behind its Zulu-based ethnic ideals (see Mdluli 1987; Gordon 1991). And Ubuntu has also been invoked by religious leaders like Desmond Tutu in an appeal to a broader African spirituality that recognises our common humanity against criminal behaviour and selfish individualism (Tutu 2004). Its troubled history notwithstanding, Ubuntu is often naively attached without much reflection to any product as a way of signalling acceptance of the new South Africa and alignment with its democratic values. Such was the case with an undergraduate curriculum at the University of Pretoria called "Ubuntu".

How Ubuntu (the curriculum) evaded my early attention is not clear, for in the sweeping reforms of five years of curriculum change at both the undergraduate and graduate levels, it had not surfaced on the modular-based curriculum radar screen. One reason might be that it was 'owned' by the Faculty of Humanities, but nevertheless prescribed as a short but intensive one-semester module required of all education students in the 


\section{PART THREE - TEACHING, LEARNING AND THE CURRICULUM}

Faculty of Education. No student could therefore obtain a degree in education without taking and passing Ubuntu.

It would probably still have avoided my scrutiny as dean were it not for the fact that more and more of the students admitted to Education were no longer only from the white Afrikaner schools. The new students coming in did their school education at black and English-speaking white schools where there was a greater sensitivity and well-honed criticality towards anything that suggested racism or patriarchy or classism. And when one of these non-traditional UP students handed me the Ubuntu course outline, I at first denied that it was even possible within my faculty; I would have known about it, I told the bemused student in front of me.

Now, as the two academics from the Faculty of Humanities sat in front of me in my dean's office, they looked terrified. They were the authors of the Ubuntu module. They represented the face of political correctness: a young black academic and a senior white Afrikaner professor. How could they be so wrong, this picture of inter-racial partnership? They looked terrified because of what I had required them to read while sitting in my office:

This course runs contrary to the basic commitments of curriculum transformation in the Faculty of Education, and works in ignorance of theoretical advances in studies on race, culture, identity and education over the past 25 years. It resurrects a conception of African culture that is primitive, inferior, monolithic, stable, and essential in its assumptions about black people. It works within an apartheid paradigm of what constitutes culture and ethnicity, neatly reinforcing myths about migration and settlement that no serious historian would defend. It presents a uniformly naïve understanding of Ubuntu, ignoring its multiple and contested meanings within recent South African history, including its specific mobilization under Zulu nationalism to promote an ethnic separateness for narrow political ends. This romanticised representation of Ubuntu might be the subject of crass commercialism in the world of business tourism, but cannot be defended in any serious scholarly context. It exaggerates difference to the point of absurdity, and reinvents white people around full or qualified concepts of "Euro-ness". By sharply juxtaposing African and European culture, all the worst excesses of apartheid's construction of racial identity are not only resurrected, it is reinforced in the minds of unsuspecting students (South Africa has "cultural groups"). It is clear that this course was conjured up in an attempt to introduce white Pretoria students to African culture in the once insular social and institutional contexts of the University of Pretoria. It was in all likelihood well-meaning, despite the commitment of error and the misrepresentation of people. The audience alone suggests that this course has no relevance after 12 years of democracy given 
the growing numbers of not-white students and not-South African students in institutions such as Tukkies. Even so, the concept of the African in the curriculum outline is presented as one persona - that is, completely ignoring the many ways of being African within both urban and rural areas; hence impossible terms such as "the African culture"! Disturbingly, there are derogatory stereotypes of Africans littered throughout the materials, made worse only by holding up "Europeans" (presumably white South Africans) as the superior culture who should, among other things, correct such behaviour by teaching Africans table manners! Further, the promotion of Ubuntu as representing contemporary practice is so incredibly out of whack with empirical reality - such as one of the highest crime rates in the world - that it begs the question as to the knowledge claims surrounding this concept. Yet, the demise of Ubuntu within South African society, if taken seriously, would have to take account of colonialism and apartheid, racism and the migrant labour system, forced evictions and the criminalisation of black people (e.g. the hated pass law system) - and on, and on. None of this is dealt with in this partial account of Ubuntu, thereby denying students access to the social context within which such terms emerged, were contested, started to change, and became marginal to mainstream society. By locking Ubuntu into these rural ideals which might never have existed, all sorts of myths and unrealities are sustained. So, for example, with the un-interrogated notion of the extended family in contexts where child-headed households are becoming widespread and AIDS has decimated any traditional concept of family, Ubuntu cannot account for change in the countryside and in the cities. This course cannot therefore be the focus of a modern/postmodern curriculum formed at the intersection of powerful global, continental, regional and national cross-currents in teacher education.

My two colleagues were clearly stunned, but what happened next placed me in the position of disbelief. "Well," said the senior professor, "we hear you and that's no problem; you are the client, and you are not happy with what we did, so we will simply revise it so that you, as client, are satisfied." 20 Everything I had just said in the angrilyworded page of criticism went completely over his head; the deep ideological dilemmas represented in the curriculum were not going to be discussed; the clear indictment of racism would not be challenged. This was a market-related problem: Humanities was the service provider and Education was the client. Like a faulty computer-disk about which the client complained, this curriculum computer-chip would simply be replaced.

20 The language of clienthood had deliberately entered the managerial discourses of the University of Pretoria, sowing up as keywords in strategic planning documents and even in the naming of its newest building at the time, the Client Services Centre. 
They did not fail to remind me, however, that this curriculum endeavour had won an institution-wide award for "innovation". The white professor half-chided me that his black woman colleague understood black culture and that this reflected her "authentic" expression of what happened in the black community. And they told me about student evaluations that showed that students (in this case, white students) really enjoyed exposure to black culture through Ubuntu. But since I was the client, they would simply change the content accordingly. "I don't think you understand a word I wrote down," I irritably told my colleagues, and asked them to leave.

\section{EMBEDDED KNOWLEDGE ACROSS THE UNIVERSITY CURRICULUM}

I decided to raise the matter with the Dean of Humanities; somewhat predictably, she saw little problem with Ubuntu and was more concerned that by withdrawing this curriculum offering from her faculty they would lose critical funding in an academic unit that was constantly under threat because of the oversupply of academic staff in relation to income generated through courses and degrees. In this faculty, expensive but lowenrolment subjects like African languages (under which Ubuntu was registered), music and drama generated only a slow stream of income as South African students shifted their attention to economics and accounting subjects at Pretoria and everywhere else. As dean of the faculty, I was far less concerned about the offensive knowledge contained in Ubuntu than about financial survival or what the institution called "viability".

Beginning to feel that perhaps I was mad, and everybody else around me normal, I took my concerns to my senior colleagues in the university administration to whom the deans reported. Their reaction was mixed, but even among those who recognised the offensive material there was little energy or interest to act on this issue and to take on institutional power on this sensitive matter. By this time my concerns had little to do with Ubuntu in the Faculty of Education: they now centred on the need to review the institutional curriculum as a whole. This was one of the most difficult times for me I could not restrict change to the Education Campus given what I now knew about the university curriculum more broadly. Curriculum review was an urgent matter for the entire university and I felt that it was important to interrupt this unexamined knowledge that continued to prepare another generation of white and now also black students for the new South Africa.

The problem with embedded knowledge is that it is not out there; it is not easily read off the outer coating of a public curriculum. It entails the things concealed in the belief and value systems of those who teach and learn and which, behind the classroom door, 
influence and direct the substance of what counts as the actual knowledge transactions among participants in learning process. Teachers might, in an authoritarian and hierarchical culture, appear to be following the new curriculum script, but this does not translate into transformative knowledge in the classroom, and the students know this. Changing curriculum without changing the curriculum makers is especially difficult under conditions of a sudden and radical social transformation. And changing a curriculum too far ahead of the teachers, those who make the curriculum come alive in the classroom, might please the politicians and bureaucrats concerned with impressing new knowledge on their subjects, but it is unlikely to rearrange the epistemological order of things in the classroom. What the teachers of the new university curriculum were struggling with was knowledge in the blood.

This is the difficulty in conducting an analysis of the institutional curriculum. Its outer features would reflect the noticeable changes in the organisational technologies demanded from a new national qualifications framework. The curriculum is presented in the form of 'exit-level' learning outcomes; each learning outcome is stated in a demonstrable action form; the achievement of specified outcomes is measured against what is called "assessment criteria"; and the combination of learning outcomes, following established rules of combination, make up a qualification. The Afrikaans universities like Pretoria are told often by government and the qualifications authority that they are most responsive to the organisational rules that must be followed in this elaborate architecture. What they are not told is that nothing in the content, nature and purposes of knowledge have changed at all behind the walls of this organisational complexity called "the university".

Knowledge in the institutional curriculum of the University of Pretoria is fixed, certain, positive, controllable, linear, and predictable. Scientific knowledge matters much more than human knowledge, for the laws of science, in this view of truth, eliminate uncertainty and rule out ideology. It follows therefore that science, engineering and technology enjoy much more institutional funding and political support than the humanities, education and commerce - the latter group regarded as constituted by a less certain and controllable knowledge than the natural sciences. Accordingly, it is no coincidence that the humanities are weakest at the Afrikaans universities and the sciences strongest. This does not mean that 'science' carried the pretence of control and neutrality during the apartheid years; it was during this time that science was deployed in the service of the racist state and it is one of the untold stories of 'truth and reconciliation' that the laboratories of the Afrikaans universities have not yet laid bare 


\section{PART THREE - TEACHING, LEARNING AND THE CURRICULUM}

their role in providing the knowledge base for justifying and upholding apartheid as ideology and as practice (see Jansen $1991 \mathrm{~b}$ ).

We now know that volkekunde provided anthropological knowledge about the 'Bushmen' that would enable their deployment as trackers for the apartheid military machinery in places like the then South West Africa (now Namibia). We know that psychology provided so-called scientific studies of black behaviour that would justify racial segregation and the hierarchy of races. We know that education theory, under the guise of fundamental pedagogics, linked teaching to Christian National Education which gave divine justification to the racial ordering of schools and society under the pretence of what was called "a science of education". We know that botanists at Pretoria named one of their species after vicious military units (like Koevoet) in gratitude for funding received from the defence force for their research. We know also that sociology provided the social theory that justified separation and made these ideological commitments available to a nationalist regime (see Du Toit 1984).

Surely this racially-tainted knowledge could not have disappeared behind the facade provided by the reformatting of qualifications in terms of standards and outcomes? Surely values, beliefs and knowledge do not simply leave embodied teachers as easily as does the external packaging of a new curriculum? By viewing curriculum as an institution, therefore, it allows one to peer inside the knowledge legacy of apartheid, and Ubuntu is the most dramatic example of what has not changed despite the busyness of aligning old content with new structures.

\section{INSIDE UBUNTU}

At first glance, AFT 253 (the classification of the Ubuntu module) comes across as a reasonable effort to introduce students to multicultural education and what it calls "tolerance" for other cultures. But on closer inspection, it represents the intact knowledge of apartheid under the guise of teaching students respect for others. The first hints of trouble lies in what Ubuntu regards as worthwhile knowledge to be assessed: at the front-end the assessment criteria indicate that students will be judged on the basis of "ordering and presentation" as well as "appearance" and "punctuality". Here, writ large, is something I found over and over again among my students - an obsession with neatness and order in presentation, the systematic nature of organising writing, the colourful pens used to illustrate composition, the near obsession with what things look like. This is not a trivial point, for what their socialisation in school and society values is how things look from the outside rather than the substance of what is submitted 
for examination. Order trumps truth, appearance matters more than content, style conquers substance.

There is a deep psychological and epistemological grounding that generates this orientation towards knowledge, and one that requires further study (see Foucalt 1986). But in the end, what remain above close intellectual and social scrutiny are the qualities of argument, the value of positions taken, the originality of ideas put forward, the risk pursued in analysis, the courage of interpretation. Order enables control over knowledge and over students, and structures what is allowed and disallowed in this tightly managed environment. This is what Louis Brenner in her excellent study on the transmission of knowledge in Muslim schools calls "controlling knowledge" - it is "the conviction that social behaviour could be controlled through the knowledge transmitted in school", but also suggests that "some knowledges are imbued with determining attributes of which individuals may not be consciously aware" (Brenner 2001:8).

With such control through order comes the management exercised over knowledge through the appeal to the logic of science. Thus asks Ubuntu in one of its assessment criteria for students' work: "Is the process (followed) scientific?" On a subject as value-laden as Ubuntu, "the scientific process" nevertheless enables knowledge and control. ${ }^{21}$

But if patterns of knowledge that continue to constrain the institutional curriculum were limited to such subtle manifestations of ideologies of order, hierarchy, control and scientism, it would in many cases not be noticed by those concerned with curriculum analysis. However, when such knowledge breaks through in the more visible claims about race, identity and culture, then analytical and political attention is forced on the subject. To illustrate, a number of samples of the curriculum will be drawn for discussion of the broader politics of knowledge signalled within each selection. Consider the scenario from a sub-heading in Ubuntu called Getting to Know Other Cultures:

21 This is the story Christi van der Westhuizen wrote about so powerfully in White Power as she courageously wrote against the dominant narrative as a 17-year-old schoolgirl at Dr EG Jansen High School in Boksburg and as a student at the Rand Afrikaans University in Johannesburg. The power of watchful authority whether in the form of the Afrikaans teacher who edits down "provocative" thinking and warns of danger (p. 1) or the university dean of students who threatens to expel her for daring to move outside the frame of acceptable knowledge of past heroes (p. 6). In these rare but revealing snapshots of young Afrikaner lives under the strain of apartheid lies a much more important story of knowledge, power and curriculum under Afrikanerdom. The discipline of knowledge keeps potential rebels and critics in place through threat: the examinations will not tolerate dissent (the high school teacher) and your degree might not happen (the dean of students). 


\section{PART THREE - TEACHING, LEARNING AND THE CURRICULUM}

Two school teachers went into a restaurant and ordered two baby chickens. The waiter set the table and completed bringing two silver bowls with lemon floating on top of the water. The two teachers looked at each other and without trying to find out from the waiter what the water was for, drank the water.

You see, in the African culture, you only wash your hands before sitting down at the table and you'll wash your hands again after eating. They did not know that in the Western culture you can hold your chicken with your fingers and wash your fingers in the silver bowl. I am sure that they struggled with the knife and fork trying to eat the baby chickens.

The only way these teachers could have known, was if someone from the Western culture who knew about table manners, could have taught them.

This scenario is read by every white education student at the University of Pretoria and every UP student who chooses Ubuntu as a module of choice. It is precisely the kind of racism that reinforces what white students bring into the university, a set of stereotypes consistent with their own socialisation. By casting whites as "Western", the story secures the notion among Afrikaners that they are non-Africans separated culturally, behaviourally and racially from black South Africans. The portrayal of black people in the $21^{\text {st }}$ century as backward and primitive diners out of touch with the basics of kitchen utensils and the modalities of restaurant dining fits perfectly with years of racist indoctrination visited on white youth. By depicting blacks as unsophisticated and at the same time placing the power of civilisation (last sentence) in white hands, this curriculum is unlikely to disturb received knowledge, but rather secure it. It is almost too easy to grant this kind of curriculum the respect of analysis, but it lies at heart of the argument that just below the external changes of the institutional curriculum to conform with new regulatory demands lies an as yet undisturbed set of assumptions about knowledge and identity in the former Afrikaans institutions.

Under another section called Finding Ubuntu in Myself, white students are treated to a picture of black people fighting amongst themselves:

[l]t was not only White South Africans who used to call Black South Africans names - Black South Africans also called other ethnic groups names. Even today there is ethnic undermining. The Zulus call the Sotho's "iZilwane" - things, the Sotho's calls the Zulus "Mapono" - the naked ones - does not make sense because all the Black groups disliked wearing clothes. That is why today South Africans refer to other Black people from other African countries as the "KKK's" Not the Kluck Klack Klan of America) that is the code or abbreviation that I discovered this Sunday at a flea market because one lady who is a "KKK" thought I am a "KKK" from Gabon. Then a black South African lady who overheard her, said to me, 
"We were also sure that you're a "KKK" meaning Kwere Kwere, a sound imitating expression meaning an ununderstandable cacophonic language ...

Holding aside, for the moment, the very poor quality of the content and the language usage especially for a university-level course, it is important to witness again what is being taught to white students through a now clearly personal account in the guise of a cultural story about black people. Blacks, like whites, act in demeaning ways towards each other. Blacks prefer a primitive way of life, eschewing clothing. Blacks in South Africa not only despise each other, they also despise blacks from other countries. Here the rationale for the continuation of white rule constantly expressed by apartheid politicians finds perfect resonance: whites are responsible for black people not annihilating each other because of their inherent tribal differences. Once again, the curriculum fits perfectly into the ideological apparatus that defines the historical knowledge about black people held by and transmitted through white South Africans to their children. The examples shared throughout the curriculum text are so outlandish that it is doubtful even the most bigoted white South African would really believe claims such as the recollection by the black lecturer that:

[a]s Black South Africans, our parents always told us that we are not supposed to fall in love with any Black person from Rhodesia - now Zimbabwe - because the people from there were cannibals. If you got married there, you will never be seen alive again.

It is truly stupefying that such an experience of intense prejudice of one person could be made the experience of "Black South Africans". It is even more distressing that for children coming in from white communities, this is the kind of knowledge that they receive about black people after apartheid. And that the chosen transmitter for this racist knowledge is a black woman.

One of the few times that I lost patience with this embedded knowledge of Others was in a sequence of exchanges with colleagues at another Afrikaans university, this time in the Free State province. I had conducted training there on research leadership and on scholarly publications. I invited colleagues who attended the publications workshop to submit abstracts and draft manuscripts electronically so that a post-workshop conversation and feedback could continue on their emerging writing ideas. Following a very positive and productive set of workshops, a young Afrikaner woman academic submitted the following abstract for comment:

Is it necessary to create new computer icons for black South African users of MS Office packages? 


\section{PART THREE - TEACHING, LEARNING AND THE CURRICULUM}

Some authors propagate a Cultural User Interface that is intuitive to a particular culture because different cultures sometimes interpret things like colours and metaphors differently. The culture of most black South Africans is very different from the culture of Americans, who created the MS Office packages. Therefore, alternative computer icons were investigated to determine whether it could be better understandable by black South African computer users. Black South Africans without a computer background, as well as black and white computer literate students, completed a questionnaire that contained icons from the MS computer program as well as alternative icons. With the exception of one command, the black South Africans without a computer background chose an alternative icon as their first choice. It is deducted from the questionnaires that black computer literature students memorize the standard icons and do not have a problem using it. If people are allowed some time to master the necessary skills, it might not be necessary to design new interfaces for black South African computer users.

I suppose I was tired. I had so much to deal with on my own campus with this embrace of essentialist knowledge of black people that it was just so difficult again, in another place, to engage young colleagues on this matter. Once again the intentions were positive, if paternalistic, and for this colleague it was an important observation: that cultural/racial difference should not be an obstacle to learning - simply give blacks more time to learn necessary skills. My response was less than tactful:

This entire research project is on shaky grounds: any assumptions of essentialism that gives blackness certain features and predictable or different behaviours from other human beings will bring you very strong criticism, if not the " $R$ " word, if you were ever to present this in intelligent company. I would urge you to drop this line of thinking altogether.

To my initial surprise, the young Afrikaner woman did not reply; from the e-mail string I found that she had referred my comments to a man, the senior man in her department at the Free State institution, and the one who apparently led this research project. I was mildly irritated by this familiar display of the white male coming to the defence of the innocent female, but found his response intriguing. True to the rules of beleefdheid (courtesy), he started by praising me for the quality of the workshops and the positive responses of his colleagues, especially the young woman. But he wanted to engage me in an opbovende (constructive) manner and let me know that they had received criticism on this topic before, but that they had also published from this research programme. Then he said the following: 
As starting point I wish to make it clear that we are not racist at all nor do we want to be read in this way. In fact, the motto for research in our department is "IT for all". Our central focus is to make IT more accessible for people with less training and exposure to technology. As such we do work on the connecting points of office packages ("Office suites") and must of necessity determine the unique needs of users in this milieu. We regard the new South Africa on the one hand as an opportunity for research and on the other hand as an opportunity to do social upliftment work. We examine culture as indicator, but as you surely know, culture does not have one definition. That is why we also look at language and make a distinction between African languages and European languages ... THEREFORE we use black and white as indicators. We do not try to place people in boxes or to stereotype them, BUT in the Free State is it surely so that in $90 \%$ of the cases Black=socially less privileged and White=socially privileged ... We would not, to use your words, "drop this line of thinking altogether". This would mean than we would have to regard four years of building and publications as having no value whatsoever.

I use this extended quotation from the e-mail exchange to point to several important markers of embedded knowledge. The first is that the narrative of whites uplifting blacks is again continuous with a neglected dimension of apartheid in scholarly work: that hand-in-hand with the racial oppression of black people went the missionary objective of whites uplifting those described as less fortunate, that is, the blacks. The problem with such knowledge of black people is that it does not ascribe this state of "less fortunate" status to white oppression; it is, rather, a natural state to which the white Christian has the responsibility for civilisation and upliftment. It is with this same reasoning in the post-1994 period that Afrikaners speak of black people as agtergeblewe (left behind) as a voluntary state of being, not as a result of a purposeful and deliberate system of discrimination. Nevertheless, what the Free State colleagues here draw attention to is a responsiveness to those left behind, a reaching out to 'all', and doing so in the name of the white race lifting the black race from its unfortunate state.

In my next response I simply declared that it was not possible for me to continue the discussion since my arguments were simply not understood and because their ideas about race were "ingrained" within Afrikaner belief systems which led them to "believe deeply in race". My colleague responded with disgust: "Don't you think you have been a little brainwashed by the injustices of the old dispensation and therefore you overreact? Is it possible that you as a brown man inherently and unconsciously think in precisely the opposite ways from what you accuse us as whites?" 


\section{THE PROBLEM OF CHANGE}

The black person at a white university is a knowledge bearer of the institutional curriculum in one of two ways. First of all there are black people, however small the numbers, who were trained within the apartheid knowledge of the Afrikaner institutions during the crucial period of the early 1990s, i.e. after the University of Pretoria opened its doors to black people, but before the advent of democracy in 1994. This small group of black people included those hired by white Afrikaners from within their own ranks, i.e. blacks who could be trusted, who bore the ideological and epistemological birthmarks of their trainers, who accepted the white supremacist knowledge of superior and inferior cultures, and who achieved their degrees and their junior level posts within white universities precisely because they 'fitted in' and 'fitted the profile' that white people held of black citizens.

Who better to keep disseminating offensive knowledge about black people than black juniors themselves, like the young lecturer in the Ubuntu tale? Of course, the junior black lecturer works under the supervision of the senior white professor, and so while the curriculum gains legitimacy within the university because of the white professorial authority, it gains credibility among white students because it is represented by the 'authentic' voice of the black lecturer. Here is another aspect of the knowledge/power nexus after apartheid that requires much more sustained analysis of the institutional curriculum than is the intention for this chapter.

For these colleagues, the junior black persons trained within the apartheid academy, curriculum change is especially difficult. With my colleagues in Education there was a rigid knowledge of race and ethnicity as biological and cultural givens, not as social and political constructions, and this made it very difficult - especially in the context of the social sciences - to begin training or reorienting colleagues in a broader theoretical understanding of received knowledge. Knowledge for these colleagues was positive and accumulated on the basis of scientific principles, not constructed, tentative and changing as a consequence of human endeavour. Even when there was an intellectual understanding of such a new orientation towards knowledge, it was very difficult to change towards ways of thinking and seeing that required a more tentative understanding of knowledge and authority.

This often led to considerable frustration on the part of black junior colleagues, as was evident in the response to the Ubuntu lecturer to criticism of her module:

I don't understand what they mean when they said 'that it is primitive'. When they say 'it's primitive, it's inferior' I didn't understand, because I felt even if they say 
that it is inferior let them say what is inferior so that I can improve ... So I found myself frustrated and not knowing what to do. You see so it's really disheartening if somebody criticizes you, but they don't say that this is how you should do it. Criticism is good, because that is how one grows, but if you are criticized but there is no answer to the criticism ... ${ }^{22}$ (emphasis added)

Once the initial disorientation had been felt, and the sting of criticism experienced, black and white colleagues from the previous knowledge regime would often (though not always) express this sentiment with various degrees of anxiety or indignation: "So, you convince me that I am wrong, now how do I get out of this? Show me how to access this new knowledge. Train me in the new methods of research. Where can I go and what can I do to appraise myself of this different thinking?" These are hard questions, and it is extremely difficult for such colleagues to change, especially for those who are older or coming towards the end of their careers. Decades of socialisation in race essentialist thinking and in epistemological fundamentalism do not yield easily to what is, in the end, knowledge in the blood. It is as hard to change for black academics as it is for white academics, and it was with this frustration in mind that I sent an SOS to 10 colleagues around the world who worked on the problem of educational change. This is what went forth, the two examples constructed from real personae with whom I worked and interacted in the Faculty of Education:

When practitioners are presented with new knowledge that demands a change of behaviour, they adopt, adapt, or avoid such knowledge; such responses are well documented in the change literature. What is less well understood is why persons might resist new knowledge especially when what is new is justified as rational, evidence-based, and holding promises of improvement.

What teachers, for example, resist is not always based simply on cognitive dissonance, a conflict between the existing knowledge constructs and beliefs of the practitioner and that proposed in new knowledge. It often resides at a much deeper level of disassociation, what I wish to call emotional knowledge.

Consider teacher Mary who for more than 30 years has taught Grade 1 reading using phonics; her success with this methodology has built her confidence and self-esteem; attracted awards and acknowledgements from peers and parents; and given her a profound sense of fulfilment that her ways of teaching reading are both effective and efficacious for the children entrusted to her care. Along comes a new methodology for teaching reading, and Mary struggles to change,

22 Taken from the text of an extended interview conducted by Heidi Esakov, a Master's student in the Faculty of Education, whose thesis is an analysis of the Ubuntu module at the University of Pretoria. 


\section{PART THREE - TEACHING, LEARNING AND THE CURRICULUM}

even though she is even persuaded intellectually to 'give the new thing a try'. Her knowledge of how to teach reading is not simply committed to the mind; it is encased in the heart, part of an emotional attachment to what it means to teach reading and to learn reading. In other words, what we have here is emotional knowledge of the subject.

Consider teacher Max who has taught South African history to Grade 11 students for more than 25 years. As a white South African, reared in the political vortex of the apartheid years, Max came to understand deeply that the history of white settlement was one of triumph over adversity, of civilisation over backwardness, of Calvinist faith against atheistic communism, of freedom against tyranny. He has lost male members of the family in the border wars, and he has witnessed the struggles of his parents against white poverty and their gradual rise, through the discipline of hard work, to a comfortable though not extravagant middle class lifestyle. Then 1994 happens, and a new history is to be taught with very different victor narratives to the ones he has come to believe, and through which he has come to order his choices in the world. For him, the teaching of history is emotional knowledge, even though he accepts, in the mind, the inevitability of a new official knowledge.

The standard intervention of governments to change teaching behaviour is training. The assumption is that teachers, when faced with the logic and appeal of an innovation or reform, will make the shift towards the new knowledge. But what if the behaviour to be changed is not simply a cognitive one, in which intellectual persuasion or political coercion are the means for securing compliance? What if the barrier is emotional knowledge?

Such knowledge is not amenable to training; changing the mind is in fact not the problem. It is perfectly possible for Mary and Max to find the intellectual arguments for change reasonable, even appealing, and yet to remain emotionally committed to their beliefs about teaching reading or history. They might even give the appearance of change in their statements of teaching (e.g. course outlines), but remain emotionally committed to a very different understanding of reading and history. This emotional dissonance between official knowledge and personal knowledge invariably shows up in what they choose to teach, how they teach it, and with what levels of commitment.

In this regard it is important to state that emotional knowledge is not emotional intelligence, that ability to perceive and express emotion, to express feelings that advance learning, and to regulate personal emotions in the face of conflict. In fact, Mary and Max might find it very difficult to articulate or express what exactly it is that underpins their beliefs and emotions; they might even wish to demonstrate their ability to change, their acceptance of the new knowledge. Emotional knowledge is therefore not knowledge of emotions, the latter being 
the subject of considerable research and conjecture. Does the literature on educational change have anything to say to, or about, emotional knowledge?

Perhaps not surprisingly, none of my international colleagues came back with any concrete suggestions from the literature on educational change, because this was new terrain. In these examples, the politics of emotional knowledge takes the literature beyond what it is comfortable with: first-order knowledge claims that emotions play a crucial role in decision making about everyday things and especially in the context of educational judgments. What the literature, as it stands, does not grapple with is power and especially racial configurations of power and how this plays out in a transition where power changes hands from a white minority to a black majority. Politics, in this otherwise sensitive literature on emotions, had not yet emerged as an intellectual meeting place between human emotions and racial power. And this was the heart of the curriculum dilemma with which I was struggling in a conservative institution where there was little support for, and even less understanding of, the harsh terrain of transformation on the knowledge front.

I have since come to a few tentative conclusions about the problem of curriculum change where the focus is transmitted knowledge and where the agents of change and continuity are real humans caught in the middle of a radical transition from longestablished racial rule towards a non-racial democracy. The first conclusion is that changing what people believe deeply about race, identity and knowledge is much, much more difficult than changing from say traditional mathematics to new mathematics. Both are difficult to accomplish, but emotionally held beliefs are attached to the soul in ways that are different where the subject of change is a new set of instructional technologies. There is no literature on such complexity, and the problems of changing emotional knowledge will require much more research and theory than has been possible in this text.

The second conclusion is that for some actors within a human endeavour such as schooling, change is simply too difficult. This is clearly not a training problem, for the nature of the dilemmas faced by teacher Max are so deep and complex that no amount of 'training' would be able to dislodge at an emotional level what Max believes even though intellectual consent to the change project can be achieved. It might even be unethical to demand that someone like Max should change under the terms of the new regime, for whole belief systems and indeed a personal sense of worthiness are now to be had. This position clearly requires further ethical and philosophical thought. 


\section{PART THREE - TEACHING, LEARNING AND THE CURRICULUM}

The third conclusion is that for this kind of change to even start, the in-house black (and white) academics must be balanced in staffing plans by a completely new incoming stream of black (and white) academics from outside of the resident social and epistemological world, and that they work closely together over long periods of time learning the new languages and discourses of humanness and change beyond racial essences and knowledge fixedness. This is perhaps the most profound argument for the transformation of racialised patterns of staffing in former white universities; the challenge of transforming received knowledge.

The fourth conclusion is that this kind of change makes severe demands on the second kind of black academic in a place like Pretoria, those coming from the outside. These are the black scholars who know differently and who are schooled in 'structures of thought' perceived to be threatening to resident knowledge. They do not respect authority as much as they respect ideas. They respond better to leadership persuasion than to leadership edict. They are much more perverse in their reading lists than in the one true knowledge - scientific determinism - that dominates Afrikaans universities. They are more comfortable with open relationships across race and gender than the long-term residents. They experience tremendous frustration with the randomness with which power is wielded. They feel excluded from dominant cultural representations of knowledge and power. They feel that they have to make basic arguments about simple things, and this sometimes generates extreme feelings about marginality. And then they are tempted to leave, or not to come in the first place (see Tabensky 2004). It is this strangeness of knowledge that keeps outsiders marginal.

The fifth conclusion is that leadership matters in changing the institutional curriculum. Hierarchy works well when the senior leadership has democratic instincts and is able to advance change at a pace that would not be tolerated in universities more accustomed to a broader participatory ethos. Hierarchy, however, can also damn transformation when senior leadership seeks to conserve and protect the racial status quo and insist on investing all authority within itself. In the latter case strategy and position, while suggesting change, can in fact constrain it. For example, consider the university leader who decided to have white Afrikaner colleagues lead workshops on diversity on the Pretoria campus! I repeatedly raised objections arguing that you could not ask those who were shaped by, and benefitted from, social and institutional racism to be the same persons leading its undoing. Or in the memorable words of Audrey Lorde (1984), "The Master's tools can never dismantle the Master's house." Given the hierarchy, those objections fell on deaf ears, but at least the claim could be made that 'diversity' was receiving attention. 


\section{WHAT UBUNTU SAYS ABOUT THE INSTITUTIONAL CURRICULUM}

The curriculum analysis has pointed to three key concerns revealed in Ubuntu: the common sense of racial essences, knowledge scientism, and identity hierarchies. Ubuntu reinforces the notion that there are races and that race is real, given and fixed, and therefore that racial differences should be the starting point for student understanding. This essentialist understanding of race was the foundation on which apartheid established its legitimacy, especially among white people, and it was the notion of unbridgeable divides based on colour that justified the rigidities of social segregation. From this understanding the most extreme forms of repression could be visited on any of those who rebelled against apartheid, white or black. Ubuntu therefore resonated perfectly with incoming white student understandings that they received in family, church and cultural or peer groups en route to university.

It is also important to note in the curriculum text the easy exchange between culture and race. 'Race' remains a sensitive wording in post-1994 South Africa, though Ubuntu is less reserved about this kind of language. Still, cultural essences on how blacks behave substitute for racial essences about who blacks are. And in the Ubuntu narrative, ALL blacks are implicated in the allegedly aberrant behaviour - rural blacks, urban blacks, educated blacks, illiterate blacks. A single observation is a racially universal observation, and again this is the kind of racist logic that fits comfortably within the apartheid-originating understandings of white South Africans.

That such knowledge of race - and everything else - is founded on a scientific understanding of human behaviour is another important foundational plank of the institutional curriculum. Knowledge, as indicated earlier, is fixed, certain, predictable and knowable. Science so conceived removes "ideology" and "politics" from the conversation and reasonable people would therefore accept the status quo as given by higher (that is, scientific) authority. Knowledge in this understanding both imposes control over reality and is itself controlled by the rules of science. The word wetenskaplik (scientific) is therefore extended beyond the natural sciences to every subject of study from political science (called "political studies" or "politics" in other universities) to pedagogical sciences (called "educational studies" in other institutions). ${ }^{23}$

23 I did notice, however, the return of the entry 'science' into educational discourses in the United States in part because of the need to assert the scientific basis for educational inquiry and in part because of the evidence-based movement (with its roots in the medical sciences) driven from some quarters, including the federal government under George W Bush. 


\section{PART THREE - TEACHING, LEARNING AND THE CURRICULUM}

It is not only that knowledge is fixed and races are given, but there is a distinct hierarchy among human beings with whites higher on the plane of civilisation and blacks lower in everything as indicated in their cultural practices. On the one hand Ubuntu, in essentialising black behaviour, desires whites to understand these lower behaviours (this is the crux of the multicultural education endeavour in the curriculum) rather than condemn such lifestyles and choices. On the other hand, Ubuntu requires those higher on the plane of civilisation to reach down, educate and uplift blacks so that they can come to a common and therefore white understanding of appropriate behaviour. This theme runs throughout the Ubuntu curriculum, with more than a hint of encouraging white amusement as these extreme stories of black aberration are handed to incoming white students.

Ubuntu's problem is not that it peddles this offensive knowledge on a university campus; its dilemma is that it makes explicit what is often concealed in white understandings of the Other and which is less evident in the knowledge, values and beliefs that underpin the supposedly neutral scientific knowledge presented across the institutional disciplines. To understand how Ubuntu is received as 'normal' within the institutional curriculum, the question must be posed: How did this curriculum pass approval at the level of the department, the faculty and, ultimately, the Senate of the university as a whole? Furthermore, how did this curriculum - reviewed intensely by a university-wide innovation committee - actually win an institutional award for Innovation? The answer is simple: it resonates deeply with white understandings in this Afrikaans university about what counts as legitimate knowledge of other people.

\section{CURRICULUM CHANGE: AN APPRAISAL}

I realised early on that changing the institutional curriculum was always going to be incomplete. Even as dean of a faculty in an authority-driven university, I did not have the energy or power to ensure that a completely new knowledge would sweep teaching, learning and assessment within the broad teacher education curriculum across two schools, seven academic departments, five faculty centres and any number of curriculum and research committees. The more than 500 modules made it almost impossible to scrutinise each and every learning unit to determine the extent to which it shifted the deeper understandings of race, knowledge and identity towards a more open, tentative and democratic knowledge of school and society. We decided on a number of strategies to support curriculum renewal with education. 
The first strategy was to conduct early-on departmental and programme reviews of the organisational units. In addition, external experts from other-minded universities and associates from leading international universities were requested to review the curriculum. Predictably, the reports pointed to the conservative nature of faculty knowledge, the distance of our curriculum from mainstream thinking in the disciplines, the anachronistic naming of some of our departments (like teacher training), and the narrow and instrumental character of teacher education knowledge at the expense of theoretical understanding. We used these reports to steer discussions within schools and departments about the need for change, and even made operational lists of 'things that needed to be done' to change the curriculum.

The second strategy was to appoint to headships a balance of persons from outside of the Afrikaans universities, but this was balanced with younger resident academics who showed an understanding of the larger change project and who were willing to take on board the imperative of knowledge transformation on which we deliberated. The theory was that with the right school-and departmental-level leadership the knowledge base of teacher education could be interrogated and academics within a unit could be inspired and led to change their values, knowledge and beliefs. Regular and intensive workshops and meetings were held with these unit leaders to develop a coherent and shared understanding of what we wanted to achieve with curriculum change.

The third strategy was to change the inherited names of schools and departments as far as possible. Thus "psychopedagogics" became educational psychology and "sociopedagogics" became the sociology of education, while "curriculum studies" replaced "department of didactics". The School of Educational Studies reflected in its new names the academic character of the faculty rather than its "teacher training" designation which reduced the intellectual endeavours of teaching to little more than training; of course, another school called "teacher training" was then established for reasons discussed later.

The fourth strategy was to change the criteria by which intellectual work was assessed. New and elaborate schemata changed the faculty promotion rating scales in favour of intellectual depth, creativity and originality (literally these words) rather than simply the production of large numbers of publication units. The evaluation of especially doctoral dissertations required a new set of performance standards that included contributions to new knowledge and innovation in theory and method; and the community of scholars involved (or required to be involved by faculty regulation) in the 'moderation' of student examinations was now drawn from a more cosmopolitan crew of national 


\section{PART THREE - TEACHING, LEARNING AND THE CURRICULUM}

and international academics. The logic here was that by changing what was valued at the level of terminal outcomes or performance criteria, there would be a backwash effect onto knowledge and curriculum in the classroom.

There is little doubt that the combination of these strategies started to erode certain and fixed knowledge, and that as the standards of knowledge changed, different kinds of faculty and different kinds of academic work started to be noticed, and started to appear for evaluation. The university administration, to be fair, acknowledged and even admired these qualitative shifts in the academic culture of Education, and some even commented that we might be too 'strict' in what we required of academic quality and performance. Of course such attempts to change the deep structures of knowledge with their encasing beliefs and values cannot happen simply by changing what is valued, for reasons revealed later.

\section{THE TENSIONS BETWEEN DEE CHANGE AND MANDATED CHANGE}

In the meantime, though, this attempt to revise the institutional curriculum at the level of the faculty had to compete with an even more compelling (from the perspective of the university administration) change project and that was to align the individual faculty curricula with the formats and standards of the South African Qualifications Authority (SAQA). This largely technical exercise did even less for knowledge transformation, even though the idea of placing all qualifications on a national framework expressed more idealistic ambitions for curriculum transformation. The energies of every academic were clearly devoted to this curriculum alignment exercise - it was easier to do, it did not question underlying belief systems, it did not disturb received knowledge, and it came with senior management instruction, die opdrag (the command) that pushed aside any other kinds of political and intellectual efforts to interrogate concealed knowledge.

In the midst of these efforts to change deeply the knowledge base of teaching came yet another overarching administrative command system called "quality assurance". Once again, hundreds of faculty hours would be diverted into preparing documentation for the new quality assurance review of a statutory body called the Council on Higher Education which, through its Higher Education Quality Committee (HEQC), made final judgments about the approval or closing down of funded programmes. The significance of attaining accreditation, without which no programmes could be offered, held severe repercussions for institutional reputation and faculty funding. Once again the energies of the staff were pushed towards compliance with external regulation with considerable pressure, of course, from central administration. 
The point of this discussion is that energetic pursuits of curriculum change seeking social justice and corrective knowledge are severely impeded when they happen in overarching social contexts where a new government places added regulatory frameworks over universities that demand and win the attention of academics and administrators within them. It is therefore not only the difficulty of changing a microenvironment (one faculty, Education) within a macro-institutional context that is so difficult; it is the added dimension of state regulatory changes that further complicates the process of change within an academic unit such as a faculty of Education. The academics concerned feel the burden of what they experience as one wave of change after another; they feel tired and frustrated trying to read the new rules of the game. The problem is that there are multiple and competing rules for change, and under such pressure, white (and indeed black) academics tend to lean towards those change forces which come from the higher authority and which pose the greater threat to the academic standing and employment security of staff.

Here then is the complex of curriculum change during periods of dramatic social transition. Changes happen simultaneously at multiple levels - the department, the faculty, the university, and the society. Each level of change has its own script and its own academic and ideological demands. Some demands are intellectual and others are bureaucratic; some seek compliance with set rules and others seek changes in beliefs and behaviours; some threaten personal and institutional penalties and others remain mainly exhortatory in nature; for some reforms the guidelines for change are relatively straightforward and technical, for others the change demands are more political and personal. When this happens, academics find it much easier to work with the technical and the regulatory rather than with the infinitely more troublesome changes that demand deep personal and emotional changes in understanding and commitment.

Beyond Ubuntu, smaller and less dramatic changes in the curriculum knowledge and ideologies were hard to shift. It was difficult to convince a colleague that a course on family and sex education was little more than an attempt to convince black students (the main if not exclusive audience) about the dangers of sexual liaison and the problem of HIV/AIDS; and that sexual correction and the promotion of a particular version of Christian living was not the goal of a university curriculum. It was hard to persuade my colleagues teaching about school discipline that it was important to go beyond teaching the different techniques of keeping children under control and to bring in Michel Foucault and others to grapple with the meanings of punishment and its institutionalisation under years of apartheid. It was especially difficult to convince 


\section{PART THREE - TEACHING, LEARNING AND THE CURRICULUM}

colleagues about the contested standards of knowledge and the multiplicity of ways of knowing beyond the quantitative worlds of experimental science.

The supreme test of change proclaimed in new academic policies, pursued through a broad array of training programmes and engineered through bringing in new academics from outside the political and epistemological worlds of the Afrikaans university was, of course, what happened inside classrooms. Away from the foreboding offices of leadership and at some distance from the surveillance schemes of the new government bureaucracy, what did the curriculum-in-practice actually look like? There were three responses from the resident academics in how they expressed the curriculum in practice.

It must be remembered that this new knowledge was deeply disturbing and in some ways quite foreign to resident knowledge. Moreover, this new knowledge was disempowering, for the resident academic often experienced it as a message which held that everything they thought was true, was not. Suddenly there were crises of confidence in what colleagues knew, and some saw immediately that their doctoral degrees were of little value in this swirl of change that came into education.

The first response was to engage seriously and make sense of this new curricular knowledge. This response generally came from younger colleagues who either recognised the weaknesses of their received knowledge and/or saw the practical and personal interests that could be served by adapting as soon as possible to the new curricular demands. Sometimes this eagerness was reflected in a new language spoken, but often did not manifest in a new practice expressed in the classroom. I reviewed syllabi and gave feedback on revised curricula; we organised countless seminars and writing review sessions during which colleagues could gently access the new discourses and find ways of translating the new curriculum into their practices. For many - though not all - of these colleagues, this intense engagement led to higher levels of productivity, appearances in a broader range of scholarly journals, and eventually awards and recognition in South Africa and abroad.

Gradually, the writing and the teaching of these colleagues became more flexible, new reading lists were engaged in some depth, and the epistemological character of their beliefs started to show up as deep understandings of the new knowledge. This process of transformation is of course never complete, and every now and again there is evidence of the old, but at least for this group of younger scholars (not necessarily in age, but in terms of recent entrance to the academy) there was a reawakening that was 
expressed in terms of intense joy as they recognised, for the first time, the constrictions and the constructions of knowledge within which they had hitherto been bound.

The second response was outright rejection of the new curriculum, but never directly. The institutional culture did not allow for direct confrontation with authority; the way to do this was to feign allegiance to the new knowledge, but to continue in practice with the resident knowledge. I never believed that such responses to the new curriculum orientation were ever a deliberate attempt to undermine the new knowledge; it was simply too difficult and too risky to even begin to open up to these new demands. These were often older colleagues, often very gracious persons, but for whom the changes had come too late in their careers to hold any personal benefits and so radical in ambition that they would expose the limitations of existing knowledge. Such colleagues simply stood back and continued what they were doing, quietly hoping that there would be no external or internal pressure that forced change.

As dean I did not intervene. How does one coerce change that academics simply do not believe in? What kind of change results from compulsion? And again, is it ethical to demand change when it flies in the face of what people feel competent to do? And is a university not a place in which all kinds of knowledges - unless they are clearly offensive - should be tolerated? Fortunately this was a very small group.

The third response to the new curriculum orientation was the most difficult for me to deal with from the point of view of leadership. This came from a small group of colleagues who wanted to engage the new curriculum knowledge, but found the task very difficult. They would attend all the seminars and workshops, and they would frequently set up one-on-one meetings to make sense of the content and direction of what was required, but they were simply not able to make this transition. There were several reasons for their dilemma. The one was their poor intellectual grounding in the undergraduate and initial postgraduate training that simply had not prepared them for this level of teaching and inquiry; the second and related reason is that they should never have been appointed to university positions in the first place. This sounds harsh, but it reflected a reality that came with a number of structural reforms in the post1994 university environment - the forced incorporation of college-level personnel into universities. And there was another reason - those older academics who stayed on and supported the curriculum changes, but simply could not make the transition.

It is important for the education change literature to come to terms with this reality rather than succumb to that eternal optimism of Western change writings - everyone can change. In the restrictive labour relations regime of the new South Africa that 


\section{PART THREE - TEACHING, LEARNING AND THE CURRICULUM}

protects workers in ways that make it very difficult to prove and act on incompetence, and in the racially sensitive political environment of transition, it would be very difficult to deal with this dilemma. More importantly, how does one release someone who through no fault of their own - but as a result of the harsh consequences of history found themselves marginalised and disempowered under new social and intellectual demands? And how, in such a context, does one release someone who does everything to demonstrate enthusiasm for the new curriculum and the project of change, even though they cannot?

\section{CONCLUSION}

Ubuntu offers a rare but powerful window on the nature and authority of the institutional curriculum of the University of Pretoria, and indeed other historically Afrikaans universities; but it also sheds new light on much broader problems associated with educational change in general, and curriculum change in particular, under conditions of social transition. By viewing curriculum as an institutional matter, knowledge is seen not simply as something codified within specific subjects and disciplines with psychological (learning) intent, but as the underpinning ideological, epistemological and indeed political assumptions and beliefs that govern resident knowledge. Curriculum as syllabic knowledge, it was shown, is difficult to change, because it finds its resonance, connectedness and authority in institutional knowledge, and such knowledge is in turn embedded in emotionally-held social and historical understandings of race, identity and history. In other words, knowledge in the blood.

The white Afrikaner students who therefore enter desegregated universities from their all-white social and educational experiences, do not enter former white institutions in which new curricular knowledge has been exchanged for the old. Rather, they enter universities in which the institutional curriculum is in the throes of upheaval in part because of new regulatory demands from the outside and in part because of new intellectual demands from the inside. What is being contested, at heart, is what counts as worthwhile knowledge inside these institutions. And white students are drawn into and become part of this contested environment carrying a very powerful but indirect knowledge that will add yet another dimension of struggle to a resilient institutional curriculum. 


\section{REFERENCES}

Benatar D. 2007a. Inaugural address. Monday Paper 11 April 2007 [Online]. Available: http://www.news.uct.ac.za/mondaypaper/archives.

Benatar D. 2007b. 'Affirmative Action' not the way to tackle injustice. Monday Paper 23 April 2007 [Online]. Available: http://www.news.uct.ac.za/mondaypaper/archives.

Brenner L. 2001. Controlling Knowledge: Religion, power and schooling in a West African Muslim Society. Bloomington, Indiana: Indiana University Press.

Cloete N, Fehnel R, Maassen P, Moja T, Perold H \& Gibbon T (eds). 2006. Transformation of Higher Education: Global pressures and local realities. The Netherlands: Springer.

Du Toit BM. 1984. Missionaries, anthropologists, and the policies of the Dutch Reformed Church. The Journal of Modern African Studies, 22(4):617-632.

Erasmus Z. 2007. Governing Whiteness! Now that cannot be allowed. Monday Paper 2007 [Online]. Available: http://www.news.uct.ac.za/mondaypaper/archives.

Foucault M. 1986. The Archaeology of Knowledge (Translated from the French by AM Sheridan). London: Tavistock.

Gordon D. 1991. Inkatha and its use of the Zulu Past. History in Africa, 18:113-126.

Hall M. 2007. The case for equity. Monday Paper 2007 [Online]. Available: http://www.news. uct.ac.za/mondaypaper/archives.

Jansen JD. 1991 a. The State and Curriculum in the Transition to Socialism: The Zimbabwean Experience. Comparative Education Review, 35(1):76-91.

Jansen JD. 1991 b. Knowledge and Power in South Africa: Critical perspectives across the disciplines. Johannesburg: Skotaville Publishers.

Jansen JD. 1998. 'But our Natives are different!' Race, knowledge and power in the academy. Social Dynamics, 24(2):106-116.

Jansen JD. 2001. Why Tukkies Cannot Develop Intellectuals. Innovative Lecture Series, 11 May.

Jansen JD. 2009. Knowledge in the Blood. Cape Town: UCT Press.

Karmon A. 2007. Institutional Organization of Knowledge. Teachers College Record, 109(3):603-634.

London L. 2007. Affirmative action and the invisibility of white privilege. Monday Paper 2007 [Online]. Available: http://www.news.uct.ac.za/mondaypaper/archives.

Lorde A. 1984. Sister Outsider: Essays and speeches by Audrey Lorde. Berkeley, California: The Crossing Press.

Mbigi L. 1997. Ubuntu: The African dream in management. Johannesburg: Knowledge Resources.

Mdluli P. 1987. Ubuntu-Botho: Inkatha's 'People's Education'. Transformation, 5:60-77.

Reid WA. 1999. Curriculum as Institution and Practice: Essays in the deliberative tradition. New Jersey: Lawrence Erlbaum. 


\section{PART THREE • TEACHING, LEARNING AND THE CURRICULUM}

Reid WA. 2006. The Pursuit of Curriculum: Schooling and the public interest. Greenwich, Connecticut: Information Age Publishing.

Tabensky P. 2004. My Life at the University of Pretoria: A story of two evils. Centre for Civil Society, University of KwaZulu-Natal. Available: http://www.ukzn.ac.za/ccs.

Terwel J \& Walker D (eds). 2004. Curriculum as a Shaping Force: Toward a principles approach in curriculum theory and practice. New York: Nova Science Publishers.

Tutu D. 2004. God has a Dream: A vision of hope for our time. New York: Doubleday.

Van der Westhuizen C. 2007. White Power and the Rise and Fall of the National Party. Cape Town: Zebra Press.

Woods M. 2007. Personal e-mail communication. 20 December 2007. 